\title{
Improving Regulation of the Domestic Content of Australian Television
}

\author{
Franco Papandrea
}

L IKE most developed countries, Australia imposes minimum domestic content requirements for television programs in an attempt to protect the naAtional culture and identity from the allegedly detrimental effects of 'overconsumption' of imported programs. Such regulation has existed in Australia for more than 30 years. The current provisions mandate the broadcast of domestic programming for at least half of a station's air time between 6am and midnight (rising to 55 per cent in 1998) and the broadcast of minimum levels of adult primetime drama, documentaries and children's programming (including a quota for firstrelease children's drama). The effectiveness and efficiency of these measures have been variable, and could be improved.

\section{Why Special Regulations for Commercial Television?}

Why should domestic content of commercial television be highly regulated?

Although unique in certain respects, commercial television closely resembles other popular media. The closest substitutes for commercial television are nonadvertiser-funded television services including national free-to-air services and pay television. Other, less close, substitutes include video hire, cinemas, magazines, newspapers, radio, and computer-based information and entertainment like video games and CDROM. None of these substitutes is regulated to the same extent as commercial television, and non-television substitutes are not subject to domestic content regulation.

Television is generally regarded as an influential medium with the capacity to alter audience perceptions. It is highly prized by advertisers, who pay large amounts to broadcast their messages both to inform and to influence audiences. Similarly, programs would also appear to be influential but their effect is less obvious than that of advertising. However, television is not unique in these respects.

Television differs from other media in being readily accessible in almost every home at negligible direct cost. It is consumed in relatively large quantities (more than three hours a day on average), making it the most important leisure activity for a large proportion of the population. Thus, to the extent that external cultural

Franco Papandrea is a Research Leader in the Bureau of Transport and Communications Economics (BTCE). The views expressed in this article are those of the author and should not be attributed to the BTCE or any other organisation. 
benefits accrue from the consumption of some programs, such benefits can be gained more readily from television than from other media.

As well, it appears that television operators are biased against high-cost programs and programs that appeal to relatively small audiences (Spence \& Owen, 1977). Furthermore, because commercial broadcasters do not gain directly from the external cultural benefits generated by domestic programs, the value of those benefits is not taken into account in their programming decisions. Consequently, desirable domestic programming may be undersupplied in the absence of regulatory requirements. These characteristics of television programming choice may lead to outcomes that do not maximise social welfare.

\section{Differential Treatment of Programs}

The extent to which programs influence audiences is largely determined by their nature, content and popularity. For example, viewers are likely to treat the content of a news and current affairs program more seriously than the content of a game show. In terms of popularity, Papandrea (1996) found that the most popular, regularly watched programs were news and current affairs (80.8 per cent of respondents), movies (46.5 per cent), documentaries (41.2 per cent), sports (38.9 per cent), and serials and series (23.0 per cent). The amount of commercial television air time devoted to different categories of program may also be taken as an indicator of their relative levels of demand. Adult drama, which occupies approximately 35 per cent of commercial television air time, is by far the most regularly transmitted type of program. Light entertainment comes second, with approximately 18 per cent of air-time devoted to it (ABA, 1994).

The degree to which domestic programs compete with imported substitutes varies considerably. Domestic news, current affairs and sports programs, for example, being in high demand and generally profitable to stations, are substantially protected from imported programs. In contrast, domestic origin is not a major determinant of demand for other types of programs, particularly those primarily intended to entertain viewers.

Adult drama. Drama looms large in all discussions of Australian content regulation of television programs, and is the subject of special quota provisions. Although it is often said that drama exerts an essential and unique influence on cultural development, there is very little empirical evidence to support this claim. However, as drama is the highest-cost form of domestic programming, it could be argued that the established bias of television operators against high-cost programs is likely to lead to it being undersupplied. So if the argument that consumption of domestic drama is an essential element of cultural development is valid, regulation may be necessary to ensure that at least a representative quantity is delivered to audiences.

Although different mechanisms are used for the purpose, government intervention is a consistent characteristic of the domestic production of other forms of drama. While there are no domestic content quotas set for cinemas and video stores, production of feature films is directly supported by government funding. 
Financial support is also available for telemovies and television mini-series (in addition to the television drama quotas), but not for serials or series.

Children's programs. According to the Australian Broadcasting Tribunal (ABT, 1991:333), 'regulatory action for children's television has essentially been a response to lack of quality, age specific, television programs for children and the need to protect their interests'. The available evidence suggests there is widespread support for special consideration of the programming needs of children (Papandrea, 1996).

The need to protect children extends beyond programs to advertising, where the regulators impose controls on both the type and the quantity of advertising during children's programs. Programs for pre-school children are prohibited from carrying any advertising. These restrictions aggravate the impact of the regulation on broadcasters. Even without advertising restrictions, the naturally limited appeal of children's programs acts as a disincentive to broadcasters.

Small audiences and stringent advertising restrictions make children's programs generally unappealing to commercial broadcasters. The disincentive against broadcasting children's domestic drama is particularly acute because of its cost to broadcasters. Under such circumstances, broadcasters will be concerned primarily to minimise the cost of compliance with the regulation. Where they are required to supply a prescribed quantity of drama, the only way they can control compliance costs is to reduce the cost of production factors, which may have a potentially severe impact on program quality.

Documentaries. Specific requirements for the broadcasting of Australian documentaries were introduced in 1996. The arguments advanced for the support of documentaries are similar to those for adult drama, including cultural importance and under-representation on programming schedules.

Like drama, documentaries are costly to produce, and broadcasters are therefore likely to be biased against them. As well, their typical one-off nature makes them even more unattractive to broadcasters, irrespective of their national origin. For example, a documentary series in which each program deals with a different issue offers much less scope for the retention of audience loyalty than a drama series, with consequentially less capacity to take advantage of promotion and scheduling economies.

The $\mathrm{ABA}$ provided little justification for the introduction of specific quota levels for documentaries. Indeed, the data available when the quota was announced do not seem to support the need for a quota. Those data show that Sydney's commercial stations were already broadcasting substantially more hours of Australian documentaries than are now required by the quota (ABA, 1993). The quota is therefore unlikely to have a significant impact on the stations' future performance.

\footnotetext{
${ }^{1}$ See Papandrea (1994) for a discussion of the difficulties in defining program quality.
} 
Program diversity. A major potential argument for intervention in television programming is that competitive commercial operators supply a less than desirable level of program diversity. Duplication of the type of program already supplied on another channel is more profitable to a competing broadcaster if, after adjusting for differences in program costs, it can attract a bigger audience than by broadcasting a different type of program.

A Bureau of Transport and Communications Economics (BTCE) report examined the changes in the level of program diversity (defined in terms of the number of different types of programs available to viewers) when additional commercial stations are introduced in a market. It found that the addition of two stations increased the maximum weekly diversity index from 1.00 to 2.06 , and that a change from two to three stations increased the weekly index from 1.63 to 2.06 . By way of comparison, two stations showing different types of programs in each time slot would have achieved an index of 2.00 . The report also noted that the presence of the $\mathrm{ABC}$ in a television market provided an 'important additional level of diversity to viewers' (BTCE, 1991:116). In an earlier econometric study of television viewing, Withers (1985) reported similar results on the effect of the ABC.

\section{Regulation and Technological Change}

Regulation or other market intervention is desirable only if it leads to an improvement in social welfare. The necessary conditions for justified market intervention include the presence of market failure and the delivery of benefits that exceed the cost of intervention. But if regulation is justified, it is necessary to establish whether the instruments used are, and are likely to continue to be, the most effective and efficient for the purpose.

Rapid technological change in all communication industries, including television, raises doubts about the continued effectiveness and efficiency of current regulations. Historically, the broadcasting and communications industries supplied distinct services, which facilitated the application of differential regulation. But with changing technology, a given service can be provided by a variety of means (such as frec-to-air broadcasting, cable, microwave, satellite, and so on). The Broadcasting Services Act 1992 attempted to circumvent the effects of technological change by defining broadcasting as services to the general public independently of the means of delivery. The Act also defines 'narrowcasting' services (which are not subject to domestic content regulation) as services to specific groups (defined geographically or by interests). However, the likely segmentation of audiences by the evolution of a multitude of services will result in services becoming increasingly specialised, so blurring the distinction between broadcasting and narrowcasting. This is likely to reduce substantially the effectiveness of regulation designed for services reaching very large audiences.

Technological change is also likely to generate new services that may be beyond the reach of domestic regulation. Satellite services originating overseas can be accessed in Australia. Similarly, video images and entertainment services are accessi- 
ble through the Internet, and may originate in locations that are beyond the jurisdiction of domestic governments.

\section{Improving the Efficiency of Current Regulation}

Assessment of the efficiency of an intervention is based on estimates of its costs and benefits. This is not an easy task, particularly when it involves the indirect measurement of intangible benefits. To date, only Papandrea (1996) has attempted to produce such an estimate for the regulation of the domestic content of television programming. Using a contingent valuation survey, that study estimated that the value of the benefits accruing to society were at least commensurate with the cost of supplying Australian programming. With improved regulatory arrangements those benefits could be increased.

The transmission quota. Domestic content quotas have often been cited as a quid pro quo for restricted licensing of entry to the commercial television industry (BTCE, 1991). The cost of meeting the quota is a non-transparent tax aimed at collecting at least part of the monopoly rents that licensing confers on established broadcasters. As a tax instrument, a quota is cumbersome and costly to administer.

Traditionally, stations have had little if any difficulty in meeting their transmission quota obligations. The natural protection of much domestic programming, including news, current affairs and sports programs, along with its popularity, appears to have been sufficient to ensure that a large proportion of all programs is of domestic origin. In addition, any shortfall in compliance can be made up easily by screening repeats of previously broadcast programs or low-cost, low-quality, 'quota-quickies' at times when audiences are small.

A more focused regulatory instrument could improve both the effectiveness and the efficiency of the current transmission quota approach. Inclusion of all programs in a quota that affects only some of them is clearly not well focused. Exclusion of programs that are highly likely to be supplied anyway would direct the focus on to programs that are more likely to contribute to cultural objectives or are unlikely to be supplied in sufficient quantities. The European approach, which determines transmission quotas as a proportion of the air time devoted to entertainment programs that compete directly with imports, may have some merit.

Another option for improved targeting of the quota is to modify the current television station licensing fee arrangements. The nominal licence-fee rate payable by stations could be increased to reflect the current cost of the quota obligations. The actual amount of licence fees payable by stations could then be discounted on the basis of a schedule of domestic content levels. To improve the targeting of the mechanism, differential discount rates could be used to promote specific types of programs.

Transmission quotas could be made tradeable among stations in the same service area. Tradeable quotas have been recommended, and have been applied with some success, as efficient instruments of environmental regulation (Hahn, 1989; Tietenberg, 1990) in pursuit of objectives that are conceptually similar to 
those of domestic content regulation. Under such a scheme, a station would have a financial incentive to transfer any excess quota to a station having difficulty in satisfying the requirement. Such an approach would ensure maintenance of the prescribed global domestic transmission quota even though some stations may not comply with the requirement. At the same time, stations with a comparative advantage in Australian programs would have an incentive to pursue such programming to a higher degree than otherwise.

To the extent that stations choose to operate away from the mean level, the diversity of programs available to viewers would be enhanced. Because stations tend to compete with one another by duplicating programs offered in the same time slot, a move away from a fixed quota could enhance program choice for viewers. Another option is to give the $\mathrm{ABC}$ a greater role in the provision of Australian programs together with a commensurate reduction in the obligation of commercial stations. Withers (1985), for example, argues that the adoption of a complementary rather than competitive programming policy by the $\mathrm{ABC}$ would increase diversity by catering for program types that are unattractive to commercial stations.

Drama requirements. Australian drama tends to be popular with audiences, and successful programs are financially attractive to broadcasters. The production of successful drama, however, is risky. About half all new drama series (the main form of Australian drama on television) fail to attract sufficient audiences to justify continued production. Such a high failure rate constitutes a strong disincentive to television stations to invest in domestic drama because they can earn similar or better risk-adjusted returns by broadcasting competitive imported drama. To comply with the quota, stations are forced to accept the cost of an otherwise unacceptable level of risk and possibly the cost of producing some drama programs which would otherwise be discontinued due to their commercially insufficient audience appeal.

The current quota arrangements are inflexible in their application and ignore the likelihood that some stations may have a competitive advantage in the production of drama programs. This possibility is suggested by the Seven Network's success with the broadcast of Australian drama in excess of quota obligations and the apparent difficulties of the Nine Network in complying with the quota. Some flexibility in the arrangements could be achieved by the introduction of tradeable drama quotas similar to those suggested for the transmission quota arrangements. But such an approach would do little to reduce broadcasters' aversion to the high level of risk of producing successful Australian drama programs.

The disincentive to commission the production of domestic drama could be reduced by direct financial incentives such as production subsidies. The provision of a production subsidy would reduce the up-front investment required for the production of eligible programs. An added advantage of a subsidy is that, unlike a quota, the level of assistance accorded to the production of a program would be transparent. Moreover, the approach appears to be effective. For example, both New Zealand and Canada provide subsidies to encourage the production of drama programs. The Australian financial assistance arrangements for the production of 
feature films are also similar in scope. Finally, such subsidies could be directed specifically to the type of programs deemed to have the greatest influence on cultural development.

A switch from programming quotas to production subsidies would shift the cost of the regulation from broadcasters to taxpayers, unless it were accompanied by an offsetting tax on broadcasters. The current arrangements are essentially a form of indirect taxation on broadcasters. While the current licence-fee arrangements continue to apply, it may be possible to increase the rate at which they are levied to cover the cost of subsidising drama production. Alternatively, stations could be required to pay a domestic program levy expressed as a percentage of advertising revenue discounted for expenditure on independent productions. A further possibility would be to reintroduce a television viewers' licence fee to fund the subsidy, along the lines of the arrangements in place in New Zealand.

An alternative approach to specific quotas and production subsidies would be to give the national broadcasters (ABC and SBS) responsibility for supplying socially desirable programs, including drama. To remain competitive in a specialised service environment, the national broadcasters would need to develop some degree of specialisation in the services they provide. To discharge effectively such a responsibility in addition to their existing statutory obligations, the national broadcasters may require more than one channel each.

Direct provision of services could be targeted specifically to desirable programs otherwise unlikely to be supplied by commercial stations. For drama, for example, emphasis could be placed on the supply of higher-cost (higher-quality) programs. Direct provision would need to pay adequate attention to audience preferences: there would be little point in providing programs that appeal to a small minority when the primary aim of the intervention was to capture the cultural external benefits of domestic programs. As a public service, the range of programs provided would need to appeal to a broad section of the community. Different channels, or parts of the program schedule on a single channel, could be directed at different sections of the community. If such an approach were adopted, the main function of the direct service providers would be to supply desirable domestic programs as an alternative to imported programs of the same genre.

To prevent a windfall gain to broadcasters from such a move, funding of the additional responsibilities assigned to national broadcasters would need to be sourced largely from commercial broadcasters who currently bear the of cost of the regulation. For this purpose, broadcasting licence fees could be increased by an amount that is commensurate with the cost of complying with the current domestic programming obligations.

Children's drama. As noted above, the requirements for children's drama (and other children's programs) impose a substantial cost burden on broadcasters. As for other elements of the regulation, the requirements essentially constitute a tax and could be more easily collected through the existing licence-fee system. Once collected, the tax revenue could be used to subsidise the cost of producing chil- 
dren's drama and targeted to ensure adequate quality. To make the drama programs attractive to broadcasters, children's drama prices would have to be comparable to those of other children's programs.

The current arrangements require all three stations to provide similar quantities of children's programming. Often, choice is limited to one time slot with a choice of three programs with similar formats. At other times, children have to be content to watch, if allowed, programs designed to cater for adults. Under such circumstances, it may be more valuable for children to have programs catering to their needs available to them at different times.

The $\mathrm{ABC}$ has had considerable success in the production and broadcasting of children's programs. Its commitment to children's programs is not driven by the profit imperatives of commercial operators and the programs it supplies are more likely to be directed at meeting the needs of children. It may be more efficient, therefore, to require the national broadcasters to increase their supply of children's programming and to release commercial broadcasters from children's programming obligations but not necessarily from obligations to fund children's programming.

To implement such a proposal, licence fees of commercial broadcasters could be increased to cover the cost of current children's programming obligations. The funds thus collected could be allocated to the national broadcasters specifically for the production of children's programs. The quantity of children's programming broadcast by the national broadcasters would increase, giving children an opportunity to watch programs specifically made for them at times best suited to them. On the other hand, the reduction or removal of children's programs from commercial stations would reduce the choice of programs currently available to children. However, because commercial stations tend to compete with one another by broadcasting similar programs in the same time slots, the reduction in the diversity of programs available to children would be smaller.

The supply of additional programming for children by the national broadcasters could not occur without displacing other programming which might be equally socially desirable (such as educational programs for schools). Alternatively, the $\mathrm{ABC}$ or SBS could be assigned additional spectrum to broadcast children's programs and perhaps other socially desirable programming.

\section{Assessment and Prospects}

The regulation of the domestic content of television programs is an important element of the cultural policies of most developed countries. Typically, the regulation is also an arm of industry assistance and employment-creation policy. The twin objectives are inseparable even if the link between them is no longer emphasised in today's world trading environment. In any event, while the presence of external cultural benefits may provide the basis for market intervention on cultural policy grounds, intervention on industry assistance grounds would be difficult to justify.

The preceding analysis suggests that the Australian regulation is only partially effective in producing desired outcomes. While it is likely to deliver a net benefit to society, welfare could be improved by the adoption of different forms of interven- 
tion. The analysis also suggests that the present instruments are probably unsustainable in a changing technological environment.

Of the existing instruments, the transmission quota contributes least to the objectives of the regulation. Many of the domestic programs included in stations' current programming schedules would continue to be supplied even in the absence of the transmission quota. Programs such as news, current affairs and sports are not only largely protected from imports, but also enjoy a high level of popularity among viewers, and are profitable. In the entertainment area, however, stations may not supply optimal levels of domestic programming because of the likely existence of bias and market failure in the program market.

The specific requirements for children's programs and adult drama appear to be more effective in changing the market behaviour of stations. Children's programming, particularly drama, would be unlikely to feature prominently in television programming without the regulation. Similarly, but to a lesser extent, adult first-release drama would not be as prominent without the regulatory requirement. The existing instruments, therefore, could be said to be effective in meeting the objectives of the regulation.

The current regulatory mechanisms could be better targeted and modified to improve their efficiency and increase the net welfare accruing to society. Tradeable quotas, for example, would facilitate specialisation by stations in areas of programming where they have comparative advantages without reducing the overall output of desirable programming. Other mechanisms, such as production subsidies, would have the added advantages of transparency and better targeting of both the type and the quality of programs.

The unstated assumption underlying these proposals is that the industry environment will not undergo major change. While this may be a reasonable assumption in the short term, it is clearly untenable in the medium to long term. Communications technology is undergoing rapid change and the pace of change is expected to increase. The television market is already changing and will continue to do so. This is an ominous development for the effectiveness and efficiency of regulatory instruments that were designed for an era of high predictability and little change.

Given that the natural market for all communications services is becoming increasingly global, mechanisms such as programming quotas (including quotas based on proportions of programming budgets) are unlikely to retain their effectiveness. Domestic governments have no jurisdiction over programming originating outside their territory. This raises important questions for cultural policy at the national level. Given that the current regulation benefits society, appropriate policy instruments may need to be developed to ensure that the benefits will continue to flow in the new environment.

The anticipated substantial expansion of electronic information and communication services could be expected to lead to a market structure where the supply of programs will be more likely to reflect demand. To a large extent, programs with a sufficiently large private demand will be supplied by the market. Nonetheless, some 
programs that potentially generate external cultural benefits may continue to be undersupplied. In such circumstances, the current quota approach is unlikely to be effective in producing the desired outcomes, production subsidies or direct provision of socially valuable programs will be more effective. A movement towards the use of such regulatory instruments sooner, rather than later, may be appropriate. In a changing technological environment it appears that government will not be able to prescribe what is consumed and can do no better than ensure that those who value programs deemed to be socially desirable have the option of consuming them.

\section{References}

Australian Broadcasting Authority (ABA) (1993), 'Australian Content on Television: 1990-1992', Trends \& Issues 2 (October).

_- (1994), 'A Snapshot of Australian and Imported Programming', ABA Update (April): 11-13.

Australian Broadcasting Tribunal (ABT) (1991), 'Regulation of Children's Programs', pp. 329-63 in kids tv: An Inquiry into Children's Television Standands, Vol. 2, Sydney.

Bureau of Transport and Communications Fconomics (BTCE) (1991), Economic Aspects of Broadcasting Regulation, AGPS, Canberra (Report No. 71).

Hahn, R. (1989), 'Economic Prescriptions for Environmental Problems: How the Patient Followed the Doctor's Orders', Journal of Economic Perspectives 3(2): 95-114.

Papandrea, F. (1994), 'Issues of Quality in Australian Television', pp. 499-517 in Communications Research Forum 1994 Papers, Vol. 2, BTCE, Canberra.

- (1996), Mcasuring Community Benefits of Australian TV Programs, AGPS, Canberra (BTCE Occasional Paper No. 113).

Spence, M. \& B. Owen (1977), 'Television Programming, Monopolistic Competition, and Welfare', Quarterly Journal of Economics 91(1):103-26.

Tietenberg, T. (1990), 'Economic Instruments for Environmental Regulation', Oxford Review of Economic Policy 6(1): 17-33.

Withers, G. (1985), 'Television Viewing and ABC Program Policy: An Econometric Study', Australian Journal of Management 10(2): 99-112.

The author is grateful for the helpful comments of two anonymous referees on an earlier draft. 